\title{
The challenges of research participation by children
}

\author{
Frank H. Bloomfield ${ }^{1-4}$
}

U ndertaking research in vulnerable populations has its own unique challenges, and children are one such population; those with impairments are another. In this issue, Hein et al. (1) make an important contribution to our understanding of why children may not participate in research. Previously, Hein et al. reported that almost $40 \%$ of children aged between 6 and $17 \mathrm{y}$ were judged incompetent to give consent, with age a key determining factor (2). In this article, they address the reasons children decline to assent-i.e., to provide affirmative agreement to take part in research. Assent respects the child as a person, without removing the protection of parental permission. However, this does not mean that the level of understanding required to give assent is the same as that required to give consent or parental permission. The National Commission for the Protection of Human Subjects of Biomedical and Behavioral Research recommended that subjects with limited capacity should know what procedures will be performed, choose freely to undergo these procedures, communicate this choice unambiguously, and be aware of the option to withdraw (3). These recommendations allow for considerable flexibility in the tailoring of discussions for assent with children so that they are developmentally appropriate given that the protection of parental permission remains, although there remains substantial disagreement on this topic (4).

As the original study by Hein et al. was to validate a standardized competence assessment, the approach to each child is likely to have been very structured and not tailored for developmental status or to the nature of particular study under consideration. It is, therefore, perhaps not surprising that $60 \%$ of children did not assent to take part in research, either because they chose not to participate (39\%) or did not make a decision (21\%). Interestingly, on multiple logistic regression analysis, a greater degree of disease experience and increased level of complexity and risk of the study in question were associated with a greater likelihood of assent (1). Thus, lower risk and less complex research had lower participation rates. As is relatively common in research, due to the logistic and cost issues of providing translators, not being a native language speaker was an exclusion criterion. Fathers, parents with lower education levels, and those with minority status have been reported to perceive lesser degrees of voluntariness associated with research decisions for their children (5). There is often a degree of protectionism around the involvement of children with disabilities in research, leading some to argue that this leads to unequal access to the potential benefits of research (6).

These factors can combine to make embedding research as part of clinical care in children very problematic: many of the questions that need answering are simple, fundamental questions that have not been addressed in children, as reflected by the fact that $70-90 \%$ of drugs prescribed in children are off-label or unlicensed. Many of the studies that need doing urgently are low risk and involve vulnerable populations and minorities - precisely the factors outlined above that decrease participation in research. Comparative effectiveness research is low risk and provides evidence as to whether therapeutic approaches currently in use are effective and efficacious. These therapies are already in use as standard treatments-there just is not the evidence that they work. The widespread use of therapies that are not based on evidence as part of standard clinical care has been described as a lottery (7) and as "random care rather than randomized care" (8). Thus, in the vulnerable population of children, standard therapy carries risks: the treatment may not be effective, and it may even cause harm. If comparative effectiveness trials are undertaken to address this evidence gap, the risks of the standard treatment emphatically are not risks of research, although they often are portrayed as such in the information and consent process.

So how to increase uptake of children (and other minorities and vulnerable groups) into clinical trials? Alternative approaches to providing information, such as illustrated consent forms and community consultation, may be of use. There is some evidence that although illustrated consent forms are effective at conveying procedures involved in research, they are less effective at conveying concepts such as voluntariness, confidentiality, and the difference between research and clinical care (9). Increased participation in research may result from improved education of, and understanding by, the public, policy-makers, and funders that randomization to treatments that are already in use as standard care but without the evidence base to support their use is preferable to a choice of treatment that is unproven and will vary among clinicians. But perhaps the topic that really needs debate is whether, for true comparative effectiveness trials, the time has come for opt-out rather than opt-in (7) and for greater consideration of the use of

\footnotetext{
'Liggins Institute, University of Auckland, Auckland, New Zealand; ${ }^{2}$ Department of Paediatrics: Child and Youth Health, University of Auckland, Auckland, New Zealand; ${ }^{3}$ Newborn Services, National Women's Health, Auckland City Hospital, Auckland, New Zealand; ${ }^{4}$ Gravida: National Centre for Growth and Development, Auckland, New Zealand. Correspondence: Frank H. Bloomfield (f.bloomfield@auckland.ac.nz)
} 


\section{Commentary | Bloomfield}

deferred consent or waivers of consent (10) for treatments that need to be started either in an emergency setting or shortly after a very stressful admission/clinical situation, when some have argued that truly informed consent is nothing more than a nice idea (11).

An example of how the requirement for prior consent when comparing two treatments commonly used and in equipoise, without evidence of superiority for either approach, affected recruitment bias and, therefore, the generalizability of the results is provided by the Continuous positive airway pressure (CPAP) Or INtubation trial (COIN-trial) (12). Of the 2,165 babies who underwent assessment for the COIN-trial, only $28 \%$ were randomized. Consent was refused or babies were not eligible in only $25 \%$ of babies assessed; thus, over 1,000 babies who were not enrolled might have been able to participate in the trial (12). Furthermore, 94\% of the babies enrolled in the COIN-trial were exposed to antenatal corticosteroids, compared with only $85 \%$ of all babies of comparable gestation (13), demonstrating bias toward babies more likely to have had the opportunity to be exposed to antenatal corticosteroids.

Clearly, insight into why children decide not to participate in research is important and may lead to improved processes that lead to better understanding and, therefore, greater uptake of the opportunity to be involved in clinical trials. However, the findings of Hein et al. also highlight the likelihood of biased recruitment, even secondary to decisions made by the investigators for logistical reasons, such as language requirement. Children have a right to medicines and treatments that are evidenced based; they also have a right to appropriate protection due to their vulnerable status. Comparative effectiveness research with modified, but still appropriately regulated, criteria for consent/assent can deliver the former without compromising the latter.

\section{REFERENCES}

1. Hein IM, Troost PW, de Vries MC, Knibbe CA, van GoudoeverJB, Lindauer RJ. Why do children decide not to participate in clinical research: a quantitative and qualitative study. Pediatr Res; e-pub ahead of print 9 April 2015.

2. Hein IM, Troost PW, Lindeboom R, et al. Accuracy of the MacArthur competence assessment tool for clinical research (MacCAT-CR) for measuring children's competence to consent to clinical research. JAMA Pediatr 2014;168:1147-53.

3. The National Commission for the Protection of Human Subjects of Biomedical and Behavioral Research. Research Involving Those Institutionalised as Mentally Infirm. Washington, DC: The National Commission for the Protection of Human Subjects of Biomedical and Behavioral Research, 1978.

4. Roth-Cline M, Nelson RM. Parental permission and child assent in research on children. Yale J Biol Med 2013;86:291-301.

5. Miller VA, Nelson RM. Factors related to voluntary parental decisionmaking in pediatric oncology. Pediatrics 2012;129:903-9.

6. Rumney P, Anderson JA, Ryan SE. Ethics in pharmacologic research in the child with a disability. Paediatr Drugs 2015;17:61-8.

7. Modi N. Ethical pitfalls in neonatal comparative effectiveness trials. Neonatology 2014;105:350-1.

8. Australian Clinical Trials Alliance (ACTA). Report on the 2014 National Summit of Investigator-Initiated Clinical Trials Networks. Melbourne: ACTA, 2014.

9. Abdel-Rahman SM. Evaluating the effectiveness of an illustrated permission/assent form. J Immigr Minor Health; e-pub ahead of print 2 October 2014.

10. Schreiner MS, Feltman D, Wiswell T, et al. When is waiver of consent appropriate in a neonatal clinical trial? Pediatrics 2014;134:1006-12.

11. Meadow W. Informed consent is not the major ethical issue in clinical research. Am J Bioeth 2013;13:24.

12. Morley CJ, Davis PG, Doyle LW, Brion LP, Hascoet JM, Carlin JB; COIN Trial Investigators. Nasal CPAP or intubation at birth for very preterm infants. N Engl J Med 2008;358:700-8.

13. Donaghue DA for the ANZNN. The Report of the Australian and New Zealand Neonatal Network, 2002. Sydney: ANZNN, 2004. 